IZA DP No. 5798

The Role of Profit Sharing in Dual Labour Markets with Flexible Outsourcing

Erkki Koskela

Jan König

June 2011 


\title{
The Role of Profit Sharing in Dual Labour Markets with Flexible Outsourcing
}

\author{
Erkki Koskela \\ University of Helsinki \\ and IZA
}

Jan König

Freie Universität Berlin

\section{Discussion Paper No. 5798 \\ June 2011}

\author{
IZA \\ P.O. Box 7240 \\ 53072 Bonn \\ Germany \\ Phone: +49-228-3894-0 \\ Fax: +49-228-3894-180 \\ E-mail: iza@iza.org
}

Any opinions expressed here are those of the author(s) and not those of IZA. Research published in this series may include views on policy, but the institute itself takes no institutional policy positions.

The Institute for the Study of Labor (IZA) in Bonn is a local and virtual international research center and a place of communication between science, politics and business. IZA is an independent nonprofit organization supported by Deutsche Post Foundation. The center is associated with the University of Bonn and offers a stimulating research environment through its international network, workshops and conferences, data service, project support, research visits and doctoral program. IZA engages in (i) original and internationally competitive research in all fields of labor economics, (ii) development of policy concepts, and (iii) dissemination of research results and concepts to the interested public.

IZA Discussion Papers often represent preliminary work and are circulated to encourage discussion. Citation of such a paper should account for its provisional character. A revised version may be available directly from the author. 
IZA Discussion Paper No. 5798

June 2011

\section{ABSTRACT}

\section{The Role of Profit Sharing in Dual Labour Markets with Flexible Outsourcing}

We combine profit sharing for high-skilled workers and outsourcing of low-skilled tasks in partly imperfect dual domestic labour markets, when the wage rate for low-skilled worker is set by a labor union, to analyze how the implementation of profit sharing influence flexible outsourcing and low-skilled labour market outcome. Profit sharing has a positive effect on the low-skilled wage and thus an outsourcing enhancing character. Profit sharing for high-skilled workers increases the low-skilled wage and helps to decrease the wage dispersion. Concerning the employment effects there is an employment reducing effect due to higher low-skilled wage, which can be offset by the employment increasing effect of higher effort of the high-skilled worker. Therefore, the employment effects of profit sharing are ambiguous.

JEL Classification: $\quad \mathrm{J31}, \mathrm{J33}, \mathrm{J} 51$

Keywords: flexible outsourcing, profit sharing, dual labour market, employee effort

Corresponding author:

Erkki Koskela

Department of Economics

University of Helsinki

P.O. Box 17 (Arkadiankatu 7)

$\mathrm{FI}-00014$

Finland

E-mail: erkki.koskela@helsinki.fi 


\section{Introduction}

In an integrated world, marginal cost differences are the driving force for outsourcing. Especially for Western European firms, the possibility of reducing production costs is a main factor of outsourcing to Eastern European or Asian countries. ${ }^{1}$ Attended with this fact, many people fear the consequences, i.e. the loss of employment or a wage reduction, especially for low-skilled workers. However, if outsourcing leads to cost reduction, the output price falls and induces a higher product demand. This scale effect may increase labour demand. Thus, the net employment effect of outsourcing is a priori ambiguous. Due to the actuality and importance of this topic there is a growing amount of empirical research relating to the impacts of outsourcing on labour market outcomes. Most of these studies as Geishecker (2006) or Görg and Hanley (2005) conclude that wages and employment of low-skilled workers decline, but on the other hand, high-skilled workers benefit from outsourcing at least in the shortrun. In long-run analyses, such as Amiti and Wei (2005, 2006) or Olsen et al. (2004), it is shown that the negative short-run employment effect can be dampened or offset by a labour demanding effect in other sectors.

To avoid, at least in the short-run, the negative consequences, the labour market structure and the existence of a labour union with the power to avoid a wage decrease and/or to bargain with the firm over employment guarantees, play an important role. However, if the outsourced inputs are standard components and thus produced by lowskilled worker, it can be assumed, that the firm is flexible enough to decide on the amount of outsourcing after the domestic low-skilled wage determination. Thus, if lowskilled workers are represented by a labour union, outsourcing can be used as a threat to high domestic marginal production costs and will dampen the opportunity to realize a high wage level for this type of worker. ${ }^{2}$

To work against the possible consequences of outsourcing, the domestic production has to become more attractive, i.e. lower marginal production costs or higher productivity are needed. Since both wages for high-skilled and low-skilled worker affect

See e.g. Holl (2008) or Rishi and Saxena (2004).

Of course, also tasks performed by high-skilled labour can be outsourced, i.e. the "least qualified" among the high-skilled workers. However, to be simple, we assume that workers are homogenous within a group. 
the marginal production cost, there are two components to reduce marginal costs. Since typically low-skilled workers in Western Europe are unionized, the first call is difficult to realize, at least for this group. However, the second call can be realized by introducing a profit sharing scheme ${ }^{3}$, which increases motivation and identification with the firm and thus stimulates effort respectively productivity and releases.

Although, only high-skilled workers, such as managers, often realize profit sharing as part of their income ${ }^{4}$, profit sharing affects the wage determination for the high-skilled group and via the relationship of the labour inputs and the resulting profit effect also for the low-skilled workers. ${ }^{5}$ Therefore, profit sharing for high-skilled workers can enforce or dampen the fear concerning the consequences of outsourcing of low-skilled tasks.

In this paper, we combine the research concerning the labour market effects of flexible outsourcing and profit sharing for high-skilled worker with individually effort determination. From our point of view this is an important research question, since most of the studies focus on the relationship of flexible outsourcing and direct wage payments and not on the relationship to profit dependent and thus not cost relevant wage components ${ }^{6}$, which are more and more used in the compensation schemes. Thus, our central research question is: How does the implementation of profit sharing for highskilled workers influence outsourcing activities and thus the labour market outcome for low-skilled worker? As profit sharing becomes more in focus of firms, unions and the political discussion, the implications of bonus payments if firms are only profit

3 For an increasing effect on productivity, see Cable and Fitzroy (1980), while Kruse (1993) demonstrate negative a productivity effect of profit sharing.

Empirical studies as Pendleton et al. (2001) show that profit sharing is an important phenomenon in OECD countries.

5 An intuitively explanation for the influence on the high-skilled wage is the opportunity to substitute the wage income by profit income, but due to the profit income it is possible to generate the same income. Assuming that the wages for profit sharing recipients are set by a trade union, i.e. Holmlund (1990) or Weitzman (1987) show theoretically the wage decreasing effect of profit sharing. In contrast, the empirical evidence is ambiguous. See i.e. Black and Lynch (2000) for lower regular pay, while Wadhwani and Wall (1990) show that profit sharing does not reduce the wage.

$6 \quad$ For an overview about the relationship between outsourcing and wage bargaining see i.e. Perry (1997). Concerning the effects of flexible outsourcing on wage setting see Skaksen (2004), which shows that the domestic bargained wage depends positively on outsourcing costs, and Braun and Scheffel (2007b), which find that the costs of outsourcing have an ambiguous effect on the bargained wage. However, they abstracted from the heterogeneity of the labour force. The effects of outsourcing when labour is heterogeneous is analysed by Davidson et al. (2008), but they concentrate on labour market frictions that arise with search, while we focus on the role of labour unions in the case of low-skilled wage formation. Assuming homogeneous labour, König and Koskela (2011) focus on the relationship of profit sharing and labour market outcome for unionized work force. They find that in general the effects are ambiguous. 
orientated has to be analysed from a theoretical point of view by analyzing the different effects and support or confute the public opinion at least on the firm level.

We analyze these questions in a partial equilibrium model in which we assume that low-skilled workers are unionized, while high-skilled workers are not represented and thus their wages are determined by market forces. Furthermore, we assume that profit sharing is a commitment and therefore an optional offer, which is optimally set by the firm of the firm. ${ }^{7}$ In this specification ${ }^{8}$, we find that the profit participation has an individual effort augmenting effect for high-skilled workers and thus raises the firm's profit, which increases the labour demand. Due to the complementary relationship of labour types, this opens the opportunity for the labour union to pick up a higher share of this profit by demanding a higher wage for low-skilled workers. Thus, for a constant high-skilled wage, profit sharing leads to lower wage dispersion in a firm. Since profit sharing will increase the low-skilled wage and thus marginal domestic costs, it has an indirect enhancing effect on outsourcing activities. However, the employment effects of profit sharing for both types of labour are ambiguous. On the one hand, there is a labour augmenting effect via higher effort, but on the other hand there is a labour reducing effect via the induced wage increase for low-skilled workers.

We proceed as follows. Section 2 presents the framework and investigates the model in terms of labour and outsourcing demand and employee effort, while section 3 concentrates on the low-skilled wage formation and the employment effects. Section 4 concludes briefly.

\section{Basic Framework}

We analyse in a model with heterogeneous domestic workers, i.e. a dual domestic labour market, flexible international outsourcing and committed profit sharing. The production combines effective high-skilled worker services and unskilled worker

Fung (1989) assumes that profit sharing is implemented by law, but to our knowledge only in France exists an obligatory profit share system. However, the level of the share will be determined in the bargaining round between the firm and the labor union.

8 Of course, our assumptions are specific, since one could also image that the union presents both types of workers to the same degree and profit sharing is a result of the bargaining and shared with all employees. However, we focus only on the question if the profit dependence of the income for high-skilled workers is a reason for more outsourcing of low skilled tasks. Thus, and to keep the analysis simple, we neglect the above mentioned modifications. 
services. Effective skilled employment is a combination of absolute skilled employment and the effort by skilled workers, i.e. their productivity. Following empirical studies, we assume that low-skilled workers and outsourcing activities are substitutes, so that lowskilled labour services can be provided either by the firm's own workers, or obtained from abroad through international outsourcing.

Using the described specification in the introduction, the analysed timing sequence of the decisions is summarized in Figure 1.

Figure 1: sequence of events

$\begin{array}{lll}\text { stage } 1 & \text { stage } 2 & \text { stage } 3 \\ \text { profit } & \text { low-skilled wage } & \text { effort determination }\left(e_{i}\right) \text {, high-skilled and } \\ \text { sharing }(\tau) & \text { setting }\left(w_{L}\right) & \begin{array}{c}\text { low-skilled labor demand }(H \text { and } L) \text {, and } \\ \text { outsourcing }(M)\end{array}\end{array}$

Note that this timing decision implies that profit sharing is assumed to be committed at stage 1 and at stage 2 conditional on profit sharing, the labour union determines the wage for the unskilled workers by taking into account how this affects the demand for labour and outsourcing by the firm. At stage 3, the representative firm decides on domestic employment and international outsourcing. The wage of the skilled labor adjusts to the constant world market level and given for the firm, moreover, the representative skilled worker decides on effort provision given this wage level and the profit share and thus, knowing the earning components. If the earnings components are known, the representative high-skilled worker decides on effort provision at stage 3 . Therefore, the structure of actions can be interpreted as sequential decisions on three stages, were the decisions are analysed by using backward induction.

\subsection{Labour and Outsourcing Demand}

At the last stage, the representative high-skilled worker decides the effort $e_{i}$ and the representative firm decides the high-skilled labour demand $H$, the low-skilled 
labour demand $L$, and outsourcing $M$. Assuming that the price of the final good is normalized to unity ${ }^{9}$, the firm decides domestic labour demand and outsourcing to maximize the profit function

$$
\max _{L ; H ; M} \pi=F(\bar{e} H, L, M)-w_{H} H-w_{L} L-f(M),
$$

by taking the average skilled worker's effort $\bar{e}$, the low-skilled and high-skilled wages, $w_{L}$ and $w_{H}$, as well as profit share $\tau$, as given. ${ }^{10}$ The average effort is defined as $\bar{e}=\frac{1}{H} \sum_{i=1}^{H} e_{i}$, so that the impact of provision of an additional unit of effort by a single worker is $\frac{\partial \bar{e}}{\partial e_{i}}=\frac{1}{H} \cdot 11$

In order to obtain $M$ units of outsourced low-skilled labour input, we assume that firms have to spend $f(M)=0,5 c M^{2}$ with $f^{\prime}(M)>0$ and $f^{\prime \prime}(M)>0$. This cost formulation reveals that there are some other costs associated with outsourcing such as the price the intermediate goods. Such costs could be costs for quality proofing or transport, which are exponential increasing with higher outsourcing. To allow for an exponential cost increase, we model a quadratic cost function. ${ }^{12}$

We assume a Cobb-Douglas-type production function with decreasing returns to scale according to three inputs, i.e. $F(\bar{e} H, L, M)=(\bar{e} H)^{\alpha}(L+M)^{\beta}$, where the parameters $\alpha$ and $\beta$ are assumed to satisfy the assumptions $\alpha, \beta>0$ and $1-\alpha-\beta>0 .{ }^{13}$ From the production function, we can derive the marginal products of skilled labour, unskilled labour and outsourcing $F_{H}>0$ and $F_{L}=F_{M}>0$. For the

$9 \quad$ Combining this assumption with decreasing returns to scale, we ensure positive profits, which are needed for the existence of union wage bargaining. We do not focus on the simultaneous presence of imperfections in labour and product markets, and thus neglect changes in the product market. Notice, that the profit of the firm is $(1-\tau) \cdot \pi$. However, due to the modeling of profit participation as a commitment, profit sharing works as a profit tax. Due to the neutrality of this kind of tax, also in the case of a bargained profit share the domestic labour demand does not depend on profit sharing.

11 A specification, which is also common in the literature, describes effort as the fraction of working hours that the worker actually works. Since the number of working hours is normalized to 1 , the choice of an individual is $e_{i} \in(0 ; 1)$ and thus $\left(1-e_{i}\right)$ characterizes the fraction of time spent shirking. Following this, $\bar{e} H$ is the whole actual working time.

12 See e.g. Koskela and Stenbacka (2010).

13 Koskela and Schöb (2010) use a similar formulation of the relationship between domestic labour and outsourcing. However, they abstract from high-skilled employment in the absence of dual labour markets and focus on the effects of labour taxation on outsourcing if firms are unionized. 
cross derivatives we have $F_{H L}=F_{H M}>0$ and $F_{L M}<0$. Taking these derivatives, we can conclude that for our type of production function the domestic skilled labour input and the outsourced or domestic unskilled labour input are complements, whereas the unskilled domestic labour input and the outsourced unskilled labour input are substitutes in terms of the marginal product effects of outsourcing.

Using the marginal products we can calculate the first-order conditions characterizing the domestic skilled and unskilled labour demand and outsourcing activities as

$$
\begin{aligned}
& \pi_{H}=\frac{\alpha}{H} F-w_{H}=0 \\
& \pi_{L}=\frac{\beta}{(L+M)} F-w_{L}=0 \\
& \pi_{M}=\frac{\beta}{(L+M)} F-c M=0 .
\end{aligned}
$$

The first-order conditions (2a) and (2b) imply the relationship between the skilled $(H)$ and the unskilled labours, inclusive of outsourcing $(L+M)$, as follows

$$
H=\frac{w_{L}}{w_{H}} \frac{\alpha}{\beta}(L+M)
$$

Using (2b) and (2c) we get the demand for outsourcing as

$$
M=\frac{w_{L}}{C},
$$

where $-\frac{M_{c} c}{M}=1=\frac{M_{w_{L}} w_{L}}{M}$. According to equation (4) higher unskilled domestic wage rate and lower outsourcing costs will increase outsourcing. Substituting (3) into the production function and coming with (2b) gives the unskilled labour demand, which can be expressed as follows

$$
L=m w_{L}^{-\delta} w_{H}^{-\varepsilon} \bar{e}^{\varepsilon}-M=m w_{L}^{-\delta} w_{H}^{-\varepsilon} \bar{e}^{\varepsilon}-\left(\frac{w_{L}}{c}\right),
$$


where $m=\alpha^{\varepsilon} \cdot \beta^{\delta}>0, \delta=\frac{1-\alpha}{1-\alpha-\beta}>1$ and $\varepsilon=\frac{\alpha}{1-\alpha-\beta}>0$. According to (5), a more extensive outsourcing activity will decrease the low-skilled labour demand, which is consistent with empirical evidence. As we can see, higher own wage and cross wage and lower high-skilled effort will negatively affect the low-skilled labour demand. In the presence of outsourcing the direct own wage and cross wage elasticities of unskilled labour and the effort elasticity of the unskilled labour can be written as follows

$$
\begin{aligned}
& \eta_{L}=-\frac{\partial L}{\partial w_{L}} \frac{w_{L}}{L}=\delta+(1+\delta) \cdot \frac{M}{L} \\
& \eta_{H}=\eta_{\bar{e}}=-\frac{\partial L}{\partial w_{H}} \frac{w_{H}}{L}=\frac{\partial L}{\partial \bar{e}} \frac{\bar{e}}{L}=\varepsilon \cdot\left(1+\frac{M}{L}\right) .
\end{aligned}
$$

Of course, in the absence of outsourcing, the wage and effort elasticities are constant and smaller, i.e. $\left.\eta_{L}\right|_{M=0}=\delta$ and $\left.\eta_{\bar{e}}\right|_{M=0}=\varepsilon$.

Finally, substituting equation (5) into the relationship in equation (3) gives the labour demand for the high-skilled worker

$$
H=\frac{m \alpha}{\beta} w_{H}^{-(1+\varepsilon)} w_{L}^{1-\delta} \bar{e}^{\varepsilon},
$$

where $(1+\varepsilon)=-\frac{H_{w_{H}} w_{H}}{H}=\frac{1-\beta}{1-\alpha-\beta}>1 \quad$ and $\quad(1-\delta)=-\frac{H_{w_{L}} w_{L}}{H}=-\frac{\beta}{1-\alpha-\beta}<0$. Unlike in low-skilled labour case, these elasticities from profit function (1) are independent of outsourcing.

\subsection{Effort Formation and Direct Employment Effects for Skilled Workers}

\section{Effort Determination of Skilled Workers}

As we mentioned, profit sharing can stimulates workers effort. However, if the profit share is equally distributed between $n$ employees, there could be a free rider problem, since an individual receives only $1 / n$ of the extra profit and thus there is an incentive for shirking. In the discussion of the free-rider problem, interactions of the 
group member and peer pressure are often neglected. Due to the implementation of profit sharing there are incentives in the group to internalize the externalities of freeriding and avoiding shirking, since it sets some incentives to observe each other and interact. ${ }^{14}$ This can build up peer pressure to provide the individual effort resulting from individual utility maximization and eliminate the moral hazard problem concerning free-rider behaviour. Following Kandel and Lazear (1992), we motivate this peer pressure as a group norm. Due to the observation, the individual feels shame or guilt if the individual effort is below this norm, i.e. if the individual shirks, since it lowers the income for each team member. Due to this shame, the individual realizes a loss of utility. However, an effort above the norm will also decrease the individual utility, since now the other team member will feel shame. Thus, any deviation from the norm will lead to a utility loss and can be interpreted as a punishment. ${ }^{15}$ Since any deviation from the group norm decreases the individual utility, we model the peer pressure function as a quadratic function, which can in simple form be written as $P\left(e_{i}\right)=\left(\tilde{e}-e_{i}\right)^{2}$, where $\tilde{e}$ is the social norm and defined as the average effort of all other workers than $i$.

Modelling the utility of the individual, we assume that the utility function is additively separable and depends positive on income and negative on disutility of effort and peer pressure. The remuneration includes the wage income $w_{H}$ and the profit income $\tau \cdot \frac{\pi}{H}$. Thus, the idea behind this is that high-skilled workers are assumed to be a team. The whole team gets the profit income $\tau \cdot \pi$, which is distributed equally among the members. However, to get the profit income, it causes effort provision of a worker. Since the worker dislikes effort provision, it is associated with a disutility, which can be described by the convex function $g(e)=\gamma \cdot e^{1 / \gamma}$ with $0<\gamma<1$ so that $g^{\prime}(e)>0$ and $g^{\prime \prime}(e)>0$.

Using these assumptions, we can formalize the utility function for an employed worker in a profit sharing firm in (8a) and (8b) in a firm, where is no profit sharing

$14 \quad$ See the analysis by Holmstrom (1982), Holmstrom and Milgrom (1990) and Varian (1990). Radner (1986) shows, that in repeated games under certain conditions the free-rider problem can be eliminated even if the players cannot observe other players' actions or information, but can only observe the resulting consequences.

15 Note that this punishment is a utility loss and not an income loss, where the utility loss can be interpreted as mental harassment or social exclusion. 


$$
\begin{gathered}
v=w_{H}+\tau \cdot \frac{\pi}{H}-\gamma e_{i}^{1 / \gamma}-\left(\tilde{e}-e_{i}\right)^{2}, \\
\bar{v}=w_{H},
\end{gathered}
$$

which means that the outside option of the high-skilled workers is the market wage $w_{H}$. Therefore high-skilled workers get anywhere the same wage. However, the skilled jobs will be different with respect to their job characteristics due to the existence of a profit sharing system.

A worker's problem is to choose the level of individual effort to maximize its utility. For simplicity we assume within this framework, that every group member can verify costless the effort of the others, but the firm owner cannot do this. Furthermore, we assume Nash-behaviour, where every worker chooses his/her effort taking the effort of others as given. So there is no effect of effort provision by other workers and thus the social norm is not affected by individual effort, i.e. $\frac{\partial \tilde{e}}{\partial e_{i}}=0$ (see also Lin et al., 2002). The optimal individual provided effort level results from individual utility maximization of (8a) with respect to effort, which yields the first-order condition ${ }^{16}$

$$
v_{e}=\frac{\tau}{H} \pi_{e}-e^{(1 / \gamma)-1}+2(\tilde{e}-e)
$$

Since we focus on individual effort determination, the effect on employment will be not taken into account. Therefore, $\pi_{e}^{*}=F_{e}$ holds. Using the production function, the definition $\bar{e}=\frac{1}{H} \sum_{i=1}^{H} e_{i}$ and the labour demand for low-skilled and high-skilled workers, we find for the individual effect on profit $\pi_{e}=F_{e}=w_{H} / \bar{e}$.

Remember, that the group norm is defined as the observable average effort of all other team members. Assuming Nash-behaviour, where every worker takes the effort of the others as given, in the equilibrium, the individual chosen effort level equals the group norm, which corresponds to the average effort level of all other group members. Finally, we have $e=\tilde{e}$. Therefore, for identical workers, the individual effort also

16 The index $i$ has been dropped for notational convenience. 
equals the average effort level and effort level which would be chosen without any peer pressure. Using this, we get from solving equation (9)

$$
e=\bar{e}=\left(\frac{\tau \cdot w_{H}}{H}\right)^{\gamma}
$$

Therefore, the optimal effort by the representative skilled worker is influenced by the income parts, but outsourcing will have no direct effect. From (10) it is easy to see that for $\tau=0$ no effort will provided so that concerning our production function this means that output falls to zero. Therefore, we assume $0<\tau<1$.

Since changes in low-skilled wage and profit income affect all skilled workers, each skilled worker will adjust its effort and thus the average effort will change. These effects we derive by taking the differential of effort function (10). Here, we find $\frac{d \bar{e}}{d w_{L}}>0$ and $\frac{d \bar{e}}{d \tau}>0$ (see Appendix A), so that the low-skilled wage and profit sharing enhance productivity by increasing effort provision and positively affect labour demand indirectly, which lies in conformity with empirics. ${ }^{17}$ Since higher low-skilled wage reduces low-skilled employment due to the complementary relationship of the two types of labour, the high-skilled employment also decreases. However, decreasing highskilled employment raises the effort provision of an employed skilled worker, since the influence of an individual worker on profit increases and he/she provides more effort.

We can now summarize our findings as follows.

\section{Proposition 1:}

Profit income and low-skilled wage have an individual effort augmenting effect and thus increase productivity.

Important for the next analysis is the effort elasticity of low-skilled wage. In our framework we find $\phi=\frac{d \bar{e}}{d w_{L}} \frac{w_{L}}{\bar{e}}=\frac{(\delta-1) \cdot \gamma}{1+\gamma \cdot \varepsilon}$, where $0<\phi<1$ (see Appendix A). This means, that the low-skilled wage setting by the labour union is binding.

17 See e.g. Booth and Frank (1999) or Cable and Wilson (1990). 
Also the effect of high-skilled wage on effort provision can be illustrated. Here we find the intuitive result that $\frac{d \bar{e}}{d w_{H}}>0$. A special feature is to examine the effort elasticity in terms of high-skilled wage to study whether the Solow-condition is valid. Using our results, we find $\frac{d \bar{e}}{d w_{H}} \frac{w_{H}}{\bar{e}}=\frac{(2+\varepsilon) \cdot \gamma}{1+\gamma \cdot \varepsilon}$, so that the elasticity of effort in terms of high-skilled wage is only one, if we have the specific parameter $\gamma=1 / 2$ for the disutility of effort. ${ }^{18}$ Ensuring a binding market clearing high-skilled wage, we have to assume that $\gamma<1 / 2$. Thus the classical efficiency wage argument does not hold in our framework.

\section{Direct Employment Effects for Skilled Workers}

Since we assume a constant skilled wage $w_{H}$, the employment of high-skilled workers is described by equation (7). Thus, we can determine the direct employment effects of low-skilled wage and profit sharing by taking into account the effects of effort provision.

The low-skilled wage affects the high-skilled labour demand in a direct and an indirect way. If the low-skilled wage increases the high-skilled labour demand decreases due to the complementarity between both labour types, while the indirect mechanism is the opposite effect via effort, because higher low-skilled wage leads to higher effort, which increases high-skilled labour demand. Formally, the influence of the low-skilled wage on the employment of the high-skilled workers can be presented as $\frac{d H}{d w_{L}}=\frac{H}{w_{L}} \cdot\left[\frac{\partial H}{\partial w_{L}} \frac{w_{L}}{H}+\frac{\partial H}{\partial \bar{e}} \frac{\bar{e}}{H} \cdot \frac{d \bar{e}}{d w_{L}} \frac{w_{L}}{\bar{e}}\right]$, which can be solved by using $\frac{\partial H}{\partial w_{L}} \frac{w_{L}}{H}=1-\delta, \frac{\partial H}{\partial \bar{e}} \frac{\bar{e}}{H}=\varepsilon$ and $\frac{d \bar{e}}{d w_{L}} \frac{w_{L}}{\bar{e}}=\phi$ to (for the sign see Appendix A)

$$
\frac{d H}{d w_{L}}=\frac{H}{w_{L}} \cdot[1-\delta+\varepsilon \cdot \phi]<0
$$

18 The same result is obtained by Jellal and Zenou (2000) in a dynamic efficiency wage model without outsourcing. 
so that there is a negative relationship between the low-skilled wage and the employment of the high-skilled workers and the direct complementary effect dominates the indirect effort effect.

Profit sharing affects the high-skilled labour demand only via the provided effort. Since higher profit share enhances effort provision, which high-skilled labour demand, there is a positive direct relationship between high-skilled employment and profit sharing. Differentiating (7) with respect to profit sharing gives

$$
\frac{d H}{d \tau}=\frac{H}{\tau} \cdot\left[\frac{\partial H}{\partial \bar{e}} \frac{\bar{e}}{H} \cdot \frac{d \bar{e}}{d \tau} \frac{\tau}{\bar{e}}\right]=\frac{H}{\tau} \cdot \varepsilon \gamma>0
$$

We can now summarize our findings regarding the properties of the skilled employment in the presence of outsourcing as follows.

\section{Proposition 2:}

In the presence of flexible outsourcing

a) the wage for unskilled workers affects a firm's demand for highskilled workers in two ways, directly due to complementarity of inputs and indirectly due to induced higher effort, where the direct effect dominates and higher low-skilled wage reduces skilled employment and

b) profit sharing affects the skilled worker demand of a firm only indirectly due to the effort channel, where the induced positive effort effect of profit sharing increases the high-skilled labour demand.

These results are intuitive in our setting. Higher low-skilled wage will affect the highskilled labour demand via two channels. The first is the negative direct wage effect, which leads to a lower high-skilled demand because of the complementary relationship between low-skilled and high-skilled workers. However, this will increase the effort, which increases the high-skilled labour demand. This describes the second channel, which is a positive indirect effect. In our analysis the direct effect dominates and thus higher low-skilled wage will reduce the high-skilled labour demand. 
The positive direct effect of profit sharing can be explained as follows. Higher profit sharing will increase the effort, which leads for given wage level to a higher productivity, which increases the labour demand.

\section{Low-skilled Wage Formation and Employment Effects}

We analyse the wage formation by the monopoly labour union, which determines the wage for low-skilled workers in anticipation of optimal in-house unskilled labour demand, flexible outsourcing and the high-skilled effort and employment.

Wage Formation by the Monopoly Labour Union

The objective function of the labour union of unskilled workers is assumed to be $V=\left(w_{L}-b_{L}\right) \cdot L+b_{L} \cdot N$, where $b_{L}$ is the (exogenous) outside option available for unskilled workers and $N$ is the number of labour union members. The monopoly labour union sets the wage for the unskilled workers so as to maximize the surplus according to

$$
\begin{array}{rl}
\max _{w_{L}} & V=\left(w_{L}-b_{L}\right) \cdot L+b_{L} \cdot N \\
\text { s.t. } & L=m w_{L}^{-\delta} w_{H}^{-\varepsilon} \bar{e}^{\varepsilon}-\left(\frac{w_{L}}{c}\right)
\end{array}
$$

The first-order condition associated with problem (13) is

$$
V_{w_{L}}=\frac{L}{w_{L}}\left[w_{L}+\left(w_{L}-b_{L}\right) \frac{w_{L}}{L} \frac{d L}{d w_{L}}\right]=0
$$

where the total unskilled wage elasticity of low-skilled labour demand is $\bar{\eta}=-\frac{d L}{d w_{L}} \frac{w_{L}}{L}=-\frac{\partial L}{\partial w_{L}} \frac{w_{L}}{L}-\frac{\partial L}{\partial \bar{e}} \frac{\bar{e}}{L} \cdot \frac{d \bar{e}}{d w_{L}} \frac{w_{L}}{\bar{e}}=\eta_{L}-\phi \cdot \eta_{\bar{e}}$. Using this and simplifying the first-order condition (14) we get

$$
w_{L}\left(c, w_{H}, b_{L}, \bar{e}, \tau\right)=\left(\frac{\bar{\eta}}{\bar{\eta}-1}\right) b_{L}
$$


Note, that here this unskilled labour demand elasticity is not constant, because the unskilled labour demand depends negatively on the high-skilled wage and the unskilled wage but positively on effort and the costs of outsourcing and thus, equation (15) is an implicit formulation with $\bar{\eta}>1$ (see Appendix B) respectively $\bar{\eta} /(\bar{\eta}-1)>1$.

In order to focus on our main aim, to determine the effect of bonus payments for high-skilled worker on the unskilled wage formation, we therefore apply the implicit differentiation (for the details see Appendix B). Differentiating the wage equation (15) with respect to the unskilled wage and the profit gives

$$
\frac{d w_{L}}{d \tau}=-\frac{\frac{d \bar{\eta}}{d \tau} \frac{w_{L}}{\bar{\eta}}}{\bar{\eta}-1+\frac{d \bar{\eta}}{d w_{L}} \frac{w_{L}}{\bar{\eta}}}>0,
$$

and differentiating (15) with respect to the unskilled wage and outsourcing costs gives,

$$
\frac{d w_{L}}{d c}=-\frac{\frac{d \bar{\eta}}{d c} \frac{w_{L}}{\bar{\eta}}}{\bar{\eta}-1+\frac{d \bar{\eta}}{d w_{L}} \frac{w_{L}}{\bar{\eta}}}>0,
$$

where $\frac{d \bar{\eta}}{d w_{L}}>0, \frac{d \bar{\eta}}{d c}<0$ and $\frac{d \bar{\eta}}{d \tau}<0$. Therefore, a higher low-skilled wage will increase the total wage elasticity of domestic unskilled labour demand and higher outsourcing costs and profit share will decrease the total wage elasticity of domestic low-skilled labour demand. ${ }^{19}$ Thus, we can conclude that outsourcing cost and profit sharing raise the low-skilled wage.

Knowing this, we are able to find an answer to the question if the implementation of profit sharing for high-skilled workers raise or lower outsourcing activities. Differentiating (4) in terms of profit sharing gives

$$
\frac{d M}{d \tau}=\frac{1}{c} \underbrace{\frac{d w_{L}}{d \tau}}_{+}>0
$$

19 See Senses (2010), who provide empirical evidence for this result. 
so that the effect of outsourcing activities is driven by the effect on low-skilled wage, which is positive.

We can summarize our findings concerning the effects of outsourcing costs and profit sharing on low-skilled wage, which also determines the effect of profit sharing on outsourcing.

\section{Proposition 3:}

In the presence of flexible outsourcing

a) lower costs of outsourcing decreases the wage for low-skilled labour and

b) higher profit sharing for the skilled workers has a positive effect on the wage for unskilled labour, whereas

c) higher profit sharing for the skilled workers has an indirect enhancing effect on outsourcing.

Higher profit sharing increases profit and the skilled labour demand. Since the labour inputs are assumed to be complements, the low-skilled labour demand also raises. Thus, the union's marginal costs of an increasing wage are smaller via less dismissals and the union can set a higher wage by reaping a higher share of the increased profit. But the wage enhancing effect will also induce a higher outsourcing demand, which can be explained by the substitutability of domestic low-skilled labour services and foreign intermediate goods.

Lower outsourcing costs mean for a given low-skilled wage level a higher outsourcing demand and low-skilled labour demand becomes more elastic. Due to this fact, the union's marginal costs of a higher wage increases and therefore lower outsourcing costs induces a less aggressive wage setting to avoid outsourcing and to make integrated production more attractive. ${ }^{20}$

Knowing the low-skilled wage effect of profit sharing, we can also look at the relationship of the wage levels and thus on the impact of wage dispersion in a firm. Since it is reasonable to assume that $w_{H}>w_{L}$, where $w_{H}$ is constant from a single firm's view, we can conclude

$20 \quad$ This lies in conformity with empirics, see evidence from various countries, e.g. Feenstra and Hanson (1999) or Braun and Scheffel (2007a). 


\section{Corollary 1:}

Profit sharing for high-skilled workers decreases due to a higher wage sets by the low-skilled labour union the wage dispersion in a firm.

This is an interesting and not expected feature since due to the possibility of flexible outsourcing the low-skilled worker comes under wage pressure. However, our analysis shows that introducing profit sharing increases the wage for low-skilled workers, since the union can act more aggressive due to the labour augmenting effort effect. Because we assume a single firm and a given wage for high-skilled workers, thus profit sharing leads to a lower wage gap in that single firm.

\section{Overall Employment Effects}

Up to now we have only analyzed the direct employment effects of profit sharing. For the sake of completeness we will now demonstrate the overall effects of profit sharing for the employment, taking into account the effect on the low-skilled wage.

The effect of profit sharing on low-skilled employment can be characterized as

$$
\frac{\Delta L}{\Delta \tau}=\underbrace{\frac{\partial L}{\partial \bar{e}} \frac{d \bar{e}}{d \tau}}_{+}+\underbrace{\frac{d L}{d w_{L}} \frac{d w_{L}}{d \tau}}_{-}=\text {? with } \frac{d L}{d w_{L}}=-\bar{\eta} \cdot \frac{L}{w_{L}}<0 .
$$

The first term in equation (19) describes the positive effect of profit sharing on lowskilled labour demand, because higher profit sharing induces higher effort, which leads to an increase in high-skilled labour employment and due to the complementarity of the inputs also to an increase in low-skilled labour demand. The second term in equation (19) describes the negative effect of profit sharing on low-skilled labour demand, because higher profit sharing increases the opportunity for the trade union to set a higher wage. Due to this increase in low-skilled labour costs, the firm will engage more in outsourcing and demand less low-skilled labour. Thus we have two opposed lowskilled labour effects of a profit sharing scheme for high-skilled workers, where the overall effect is ambiguous. From this we can conclude, that it is possible to observe on

the one hand more outsourcing but on the other hand also higher low-skilled employment if the low-skilled wage increases due to profit sharing. 
Similarly, we can also determine the overall high-skilled employment effect. By using equation (7) the overall effect of profit sharing on high-skilled employment is

$$
\frac{\Delta H}{\Delta \tau}=\underbrace{\frac{d H}{d \tau}}_{+}+\underbrace{\frac{d H}{d w_{L}} \frac{d w_{L}}{d \tau}}_{-}=? .
$$

From equation (20) we see that higher profit sharing has also an ambiguous overall effect on high-skilled employment. The first term, which corresponds to equation (12), describes the known enhancing high-skilled employment effect via the effort provision, while the second term describes the negative effect via the increasing effect on the lowskilled wage, which induces a decrease in the low-skilled labour demand and, due to the complementarity of the inputs, also a decrease in the high-skilled labour demand as pointed out in equation (11). Therefore, the high-skilled employment effect also consists of two opposed effects, where the overall effect is ambiguous.

\section{Proposition 4:}

In the presence of flexible outsourcing profit sharing affects a firm's demand for high-skilled and low-skilled workers via two opposed effects. The first is the effort effect, which enhances the labour demand, whereas the low-skilled wage effect as the second working channel decreases the labour demand.

As our last results pointed out, it is possible that implementing a profit sharing scheme for high-skilled workers decreases the wage gap in a firm without losing low-skilled employment, if the induced substitution effect concerning higher low-skilled wage can be offset by the effort effect. Since bonus payments for high-skilled workers must not lead in any case to lower employment of low-skilled workers, such a compensation scheme is not as bad as it is seen in the public opinion, which argue that due to the dependence of the income on profits managers pursuit the strategy of the highestprofit, which is one reason for increasing outsourcing and lower low-skilled employment, if the domestic low-skilled labour is represented by a labour union. 


\section{Conclusions}

In this paper, we have tried to describe a framework of flexible outsourcing in a partly unionized dual labour market. In Western European countries we often observe that, unlike low-skilled workers, who are organized in labour unions, high-skilled wages are mostly determined competitively. However, high-skilled workers could also directly participate in the firm's success via profit sharing, which also affects the wage determination of low-skilled labour and also the outsourcing demand. Since especially low-skilled worker fears the consequences, i.e. lower wages and dismissal, of international outsourcing we focus on the relationship of to profit dependent remuneration parts on the labour market outcome of low-skilled workers and thus concerning these consequences.

In our analyses we have shown that the wage of the low-skilled workers will be positively affected by outsourcing costs and profit sharing for high-skilled workers. Since the high-skilled wage is constant and higher than the low-skilled wage, thus higher outsourcing costs and profit sharing reduce the wage dispersion in a single firm. Also, we find that the effect of profit sharing on outsourcing activities is indirect negatively via the low-skilled wage. Finally, we characterized the employment effects of profit sharing. Here we find that profit sharing induces higher low-skilled and highskilled labour demand via increased effort, but on the other hand decreases the labour demand for both types via the higher low-skilled wage. Thus the employment effects are ambiguous. In what follows, under certain circumstances, bonus payments for highskilled worker helps to realize the aims of adequate wage and high employment level for low-skilled workers in a certain firm and can dampen the negative labour market consequences of outsourcing of low-skilled tasks.

\section{References}

Amiti, M. and S.-J. Wei (2005): Fear of Service Outsourcing: Is It Justified?, Economic Policy 20, 307-347.

Amiti, M. and S.-J. Wei (2006): Service Offshoring, Productivity and Employment: Evidence from the US, CEPR Discussion Paper, No. 5475.

Black, S. E. and L. M. Lynch (2000): What's Driving the New Economy: The Benefits of Workplace Innovation, NBER Working Paper 7479. 
Booth, A. L. and J. Frank (1999): Earnings, Productivity, and Performed-Related Pay, Journal of Labor Economics 17, 447-463.

Braun, S. and J. Scheffel (2007a): Does International Outsourcing Depress Union Wages?, Humbold Universität Berlin, SFB 649 Discussion Paper, No. 33.

Braun, S. and J. Scheffel (2007b): A Note on the Effect of Outsourcing on Union Wages, Humbold Universität Berlin, SFB 649 Discussion Paper, No. 34.

Cable, J. R. and F. R. FitzRoy (1980): Cooperation and Productivity: Some Evidence from West Germany’s Experience, Economic Analysis and Workers Management 14, 163-190.

Cable, J. R. and N. Wilson (1990): Profit Sharing and Productivity: Some Further Evidence, Economic Journal 100, 550-555.

Davidson, C., S. J. Matuz, and A. Shevchenko (2008): Globalization and Firm Level Adjustment with Imperfect Labour Markets, Journal of International Economics 75, 295-309.

Feenstra, R.C. and G.H. Hanson (1999): The Impact of Outsourcing and HighTechnology Capital on Wages: Estimates for the United States 1979-1990, Quarterly Journal of Economics 114, 907-940.

Fung, K.-C. (1989): Profit Sharing and European Unemployment, European Economic Review 33, 1787-1798.

Geishecker, I. (2006): Does Outsourcing to Central and Eastern Europe Really Threaten Manual Workers' Jobs in Germany?, The World Economy 29, 559-583.

Görg, H. and A. Hanley (2005): Labor Demand Effects of International Outsourcing: Evidence from Plant-Level Data, International Review of Economics and Finance 14, 365-376.

Holl, A. (2008): Production Subcontracting and Location, Regional Science and Urban Economics 38, 299-309.

Holmlund, B. (1990): Profit Sharing, Wage Bargaining, and Unemployment, Economic Inquiry 28, 257-268.

Holmstrom, B. (1982): Moral Hazard in Teams, Bell Journal of Economics 13, 324-340.

Holmstrom, B. and P. Milgrom (1990): Regulating Trade among Agents, Journal of Institutional and Theoretical Economics 146, 85-105.

Jellal, M. and Y. Zenou (2000): A Dynamic Efficiency Wage Model with Learning by Doing, Economics Letters 66, 99-105.

Kandel, E. and E. P. Lazear (1992): Peer Pressure and Partnerships, Journal of Political Economy 100, 801-817.

König J. and E. Koskela (2011): Profit Sharing and Outsourcing under Labor Market Imperfection, forthcoming in Review of International Economics.

Koskela, E. and R. Schöb (2010): Outsourcing of Unionized Firms and the Impact of Labor Market Policy Reforms, Review of International Economics 18, 682-695.

Koskela, E. and R. Stenbacka (2010): Equilibrium Unemployment with Outsourcing and Wage Solidarity under Labour Market Imperfections, European Economic Review 54, 376-392. 
Kruse, D. L. (1993): Does Profit Sharing Affect Productivity?, NBER Working Paper, No. 4542.

Lin, Ch.-Ch., J.-J. Chang and Ch.-Ch. Lai (2002): Profit Sharing as a Worker Discipline Device, Economic Modelling 19, 815-828.

Olsen, K. B., R. Ibsen and N. Westergaard-Nielsen (2004): Does Outsourcing Create Unemployment? The Case of the Danish Textile and Clothing Industry, Aarhus School of Business, Working Paper, No. 05.

Pendleton, A., E. Poutsma, J. van Ommeren and C. Brester (2001): Employee Share Ownership and Profit Sharing in the European Union, Luxembourg: Office for Official Publications of the European Commission.

Perry, C. R. (1997): Outsourcing and Union Power, Journal of Labor Research 18, 521534.

Radner, R. (1986): Repeated Partnership Games with Imperfect Monitoring and No Discounting, Review of Economic Studies 53, $43-57$.

Rishi, M. and S. C. Saxena (2004): Is Outsourcing Really as Bad as It Is Made Sound? A Re-assessment and Some Perspective, Indian Journal of Economics \& Business, special issue, 63-80.

Senses, M. Z. (2010): The Effects of Outsourcing on the Elasticity of Labor Demand, Journal of International Economics 81, 89-98.

Skaksen, J. R. (2004): International Outsourcing When Labour Markets Are Unionized, Canadian Journal of Economics 37, 78-94.

Varian, H. R. (1990): Monitoring Agents with Other Agents, Journal of Institutional and Theoretical Economics 146, 153-174.

Wadhwani, S. and M. Wall (1990): The Effects of Profit Sharing on Employment, Wages, Stock Returns and Productivity: Evidence from U.K. Micro data, Economic Journal 100, 1-17.

Weitzman, M. L. (1987): Steady State Unemployment under Profit Sharing, Economic Journal 97, 86-105.

\section{Appendices}

\section{Appendix A: Comparative Statics of Effort Effects}

Differentiating the effort function (10) with respect to effort and low-skilled wage gives

$$
\left[1-\gamma \cdot\left(\frac{\tau \cdot w_{H}}{H}\right)^{\gamma-1}\left(-\frac{\tau \cdot w_{H}}{H^{2}} \cdot H_{\bar{e}}\right)\right] d \bar{e}=\left[-\gamma \cdot\left(\frac{\tau \cdot w_{H}}{H}\right)^{\gamma-1} \frac{\tau \cdot w_{H}}{H^{2}} \cdot H_{w_{L}}\right] d w_{L},
$$

By using equation (7) we have $H_{\bar{e}}=\frac{\varepsilon}{\bar{e}} \cdot H$ and $H_{w_{L}}=(1-\delta) \frac{H}{w_{L}} \quad$ so that we can simplify (A1) to 


$$
\frac{d \bar{e}}{d w_{L}}=\frac{(\delta-1) \cdot \gamma}{1+\gamma \cdot \varepsilon} \cdot \frac{\bar{e}}{w_{L}}>0,
$$

where $\delta=\frac{1-\alpha}{1-\alpha-\beta}>1$. For the effort elasticity with respect to the low-skilled wage we have $0<\phi=\frac{(\delta-1) \gamma}{1-\alpha-\beta}<1$. This holds since we rewrite this term to $\phi=\frac{\beta \gamma}{1-\alpha-\beta+\alpha \gamma}$. Because our assumptions $1-\alpha-\beta>0, \alpha ; \beta>0$ and $\gamma \in(0 ; 1)$ we have $\phi \in(0 ; 1)$. For the high-skilled employment effect of higher low-skilled wage, we need the sign of $1-\delta+\varepsilon \cdot \phi$. Using our results for $\phi$ we can rewrite this term to $-(\delta-1)+(\delta-1) \frac{\gamma \cdot \varepsilon}{1+\gamma \cdot \varepsilon}$ which leads to $-\frac{(\delta-1)}{1+\gamma \cdot \varepsilon}<0$.

\section{Appendix B: Effects of Parameters on Low-Skilled Wage}

The total wage elasticity of low-skilled labour demand is $\bar{\eta}=\eta_{L}-\phi \cdot \eta_{\bar{e}}=\delta-\phi \varepsilon+(1+\delta-\phi \varepsilon) \frac{M}{L}>1$ as one can show that $\delta>\phi \varepsilon$ and therefore also $1+\delta-\phi \varepsilon>0$.

Differentiating the implicit wage formation (15) with respect to profit share and the unskilled wage gives

$$
\begin{gathered}
\left(1-\frac{\left[(\bar{\eta}-1) \frac{d \bar{\eta}}{d w_{L}}-\bar{\eta} \frac{d \bar{\eta}}{d w_{L}}\right]}{(\bar{\eta}-1)^{2}} b_{L}\right) d w_{L}=\frac{\left[(\bar{\eta}-1) \frac{d \bar{\eta}}{d \tau}-\bar{\eta} \frac{d \bar{\eta}}{d \tau}\right]}{(\bar{\eta}-1)^{2}} b_{L} d \tau \text { which can by using } \\
b_{L}=\frac{w_{L}(\bar{\eta}-1)}{\bar{\eta}} \text { (see equation (15)) expressed as } \\
\frac{d w_{L}}{d \tau}=-\frac{\frac{d \bar{\eta}}{d \tau} \frac{w_{L}}{\bar{\eta}}}{\bar{\eta}-1+\frac{d \bar{\eta}}{d w_{L}} \frac{w_{L}}{\bar{\eta}}}
\end{gathered}
$$

Similarly, we find for differentiating the implicit wage formation (15) with respect to the outsourcing cost and the unskilled wage

$$
\frac{d w_{L}}{d c}=-\frac{\frac{d \bar{\eta}}{d c} \frac{w_{L}}{\bar{\eta}}}{\bar{\eta}-1+\frac{d \bar{\eta}}{d w_{L}} \frac{w_{L}}{\bar{\eta}}},
$$


with $\quad \bar{\eta}=-\frac{d L}{d w_{L}} \frac{w_{L}}{L}=\eta_{L}-\eta_{\bar{e}} \cdot \phi, \quad$ where $\quad \eta_{L}=(1+\delta) \cdot \frac{M}{L}+\delta, \quad \eta_{\bar{e}}=\varepsilon \cdot\left(1+\frac{M}{L}\right) \quad$ and $\phi=\frac{(\delta-1) \gamma}{1+\varepsilon \gamma}$. Thus differentiating $\bar{\eta}$ with respect to $w_{L}$ gives $\frac{d \bar{\eta}}{d w_{L}}=\frac{d \eta_{L}}{d w_{L}}-\phi \cdot \frac{d \eta_{\bar{e}}}{d w_{L}}$, where $\frac{d \eta_{L}}{d w_{L}}=\frac{(1+\delta)}{w_{L}} \frac{M}{L}(1+\bar{\eta})>0$ and $\frac{d \eta_{\bar{e}}}{d w_{L}}=\frac{\varepsilon}{w_{L}} \frac{M}{L}(1+\bar{\eta})>0$. Simplifying gives

$$
\frac{d \bar{\eta}}{d w_{L}}=\frac{M}{L \cdot w_{L}}(1+\bar{\eta}) \cdot\left[1+\delta-\frac{\varepsilon \gamma(\delta-1)}{1+\varepsilon \gamma}\right]>0,
$$

since $1+\delta-\varepsilon \phi=\frac{1+\delta+2 \varepsilon \gamma}{1+\varepsilon \gamma}>0$.

Similarly way we find for $\frac{d \bar{\eta}}{d \tau}=\frac{d \eta_{L}}{d \tau}-\phi \cdot \frac{d \eta_{\bar{e}}}{d \tau}$, with $\frac{d \eta_{L}}{d \tau}=-\frac{(1+\delta)}{\tau} \frac{M}{L}\left(1+\frac{M}{L}\right) \frac{\varepsilon \gamma}{1+\varepsilon \gamma}<0$ and $\frac{d \eta_{\bar{e}}}{d \tau}=-\frac{\varepsilon}{\tau} \frac{M}{L}\left(1+\frac{M}{L}\right) \frac{\varepsilon \gamma}{1+\varepsilon \gamma}<0$, which leads to

$$
\frac{d \bar{\eta}}{d \tau}=-\frac{\varepsilon \gamma}{1+\varepsilon \gamma}\left(1+\frac{M}{L}\right)\left[1+\delta-\frac{\varepsilon \gamma(\delta-1)}{1+\varepsilon \gamma}\right]<0 .
$$

For $\quad \frac{d \bar{\eta}}{d c}=\frac{d \eta_{L}}{d c}-\phi \cdot \frac{d \eta_{\bar{e}}}{d c}$ with $\quad \frac{d \eta_{L}}{d c}=\frac{(1+\delta)}{c} \frac{M}{L} \cdot\left(1+\frac{M}{L}\right)<0 \quad$ and $\frac{d \eta_{\bar{e}}}{d c}=\frac{\varepsilon}{c} \frac{M}{L} \cdot\left(1+\frac{M}{L}\right)<0$, we have the following

$$
\frac{d \bar{\eta}}{d c}=-\frac{M}{L \cdot c}\left(1+\frac{M}{L}\right) \cdot\left[1+\delta-\frac{\varepsilon \gamma(\delta-1)}{1+\varepsilon \gamma}\right]<0 .
$$

QED. 